\title{
O IMAGINÁRIO INDÍGENA DO BRASIL COLONIAL: SÉCULOS XVI, XVII E XVIII
}

Beatriz Gomes Rodrigues ${ }^{1,2}$, Susana de Matos Viegas ${ }^{1,3}$

${ }^{1}$ Universidade de Lisboa, ${ }^{2}$ Programa de Pós-graduação em Estudos Brasileiros, ${ }^{3}$ Pós-graduação em Antropologia, Lisboa, Portugal, E-mail: nobgr.biarodrigues@gmail.com

\section{RESUMO}

Apresenta-se o estudo do Imaginário indígena do Brasil colonial: séculos XVI, XVII e XVIII, a partir do levantamento bibliográfico a respeito do primeiro contato dos europeus com os gentios das terras recém "descobertas", visando analisar a forma que se deu a relação destas distintas sociedades ao longo do período colonial, a forma como o europeu apreendeu e compreendeu a cultura autóctone e como isso desencadeou em um conjunto de medidas e ações voltadas a estas populações.

Palavras-chave: Índios coloniais; História indígena; imaginário colonial; Brasil colônia.

\section{THE COLONIAL BRAZIL INDEGENE IMAGINARY CENTURIES XVI, XVII AND XVIII}

\section{ABSTRACT}

The study of indigenous culture imaginary of the colonial Brazil is presented: XVI, XVII and XVIII centuries, based on a bibliographical survey about the first contact of the Europeans with the Gentiles of newly discovered lands, in order to analyze the form of the relationship of these different societies throughout the colonial period, the learning and the understanding of Europeans of the indigenous culture and the how this triggered a set of measures (rules) and action aimed at these populations.

Keywords: Colonial Indians, Indigene History, Colonial Imaginary, Brazil the colony. 


\section{INTRODUÇÃO}

Os séculos XVI, XVII e XVIII foram compostos por uma vasta gama de trabalhos descritivos acerca do recém "descoberto" novo mundo. Foram realizados inúmeros e variados relatos de viagens com o intuito de reconhecimento e exploração dessas "novas" terras, estes relatos por sua vez, foram produzidos por aventureiros e cronistas que passaram por territórios tupiniquins, ou por escritores que tinham apenas curiosidade pelo tema, nem chegando a conhecer de fato o local in situ. Uma vez que os índios faziam parte deste cenário, era notória a necessidade de descrevê-los e apresenta-los ao mundo.

\section{METODOLOGIA E OBJETIVOS}

Esta pesquisa tem por objetivo apresentar os principais ideais e representações acerca do indígena brasileiro no decorrer dos séculos XVI, XVII e XVIII, abordando aspectos da construção do imaginário indígena na concepção europeia, a partir da análise de documentos e bibliografias.

\section{DISCUSSÃO}

As fontes as quais são descritas teorias sociais acerca do índio no Brasil colonial, são em sua maioria, datadas do século XVI, com versões extremamente díspares. Esses relatos se prendem, sobretudo nos hábitos indígenas que mais se contrastam com aquilo que é considerado normal na Europa. Do mesmo modo, podemos notar uma diferença nas descrições e abordagens de alguns relatos quando comparamos autores que apresentavam diferentes motivações para a criação de tal, como mostra Ruivo (2010).

O universo descritivo dos descobrimentos europeus pode ser organizado em fases discursivas e de etapas de acumulação e progressão informativas. A articulação entre a escrita e o mundo real é manifesta na diferença entre uma determinada época e outra.

Barreto propõe um entendimento das visões dos índios pelos europeus no período inicial em duas fases distintas, designadas por "idade civilizacional de apenas passagem e contato" que corresponde ao período da recém-chegada europeia ao Novo Mundo e a fase seguinte de "ocupação e fixação, de implementação de todo um espaço e tecido produtivos no universo originário" que corresponde ao período de povoamento das terras brasileiras (1992, p.95).

$\mathrm{Na}$ idade de passagem e contato são possíveis apenas descrições e relatos decorrentes de curta estadia, cuja duração vivencial é de cerca de duas semanas a dois anos. Essa fase "[...] transmite uma potencial informação com base em imediatos visíveis", encontra-se nesta fase relatos de escritores que valorizam "[...] o bom clima e a variedade do Brasil natural, bem como a ideia positiva do índio, enquanto ser primitivo, mas fisicamente belo e comportalmentalmente amistosos" (BARRETO, 1992, p.97).

A segunda fase discursiva insere-se na idade de ocupação e fixação, nesta fase os relatos dos escritores possuem uma maior acumulação de conhecimentos em relação aos aspectos pontuais e imediatos, nesta fase encontra-se com especial ênfase as cartas dos Jesuítas e dos responsáveis pelo processo de cristianização indígena.

É nesta fase de maior e de melhor conhecimento das realidades físicas e humanas do Brasil que surge, de uma forma explicita e fundamentada, a pluralidade de imagens, a natureza brasileira não deixa de ser considerada, positivamente, mas o realismo do conhecimento e do aproveitamento coloniais implica as primeiras considerações negativas sobre a extrema humanidade (BARRETO, 1992, p.97). 
A visão do índio, estabelecido na primeira fase como algo positivo e de extrema inocência e docilidade, altera-se completamente, a imagem do dócil e inocente cede lugar ao ser violento e sem qualidades de trabalho ou valores morais, a fácil cristianização passa pelas dificuldades postas pelo animismo. Esta fase representa "uma maior desvalorização do outro, por uma maior presença da memória e da utensilagem classificativas europeias" (BARRETO, 1992, p.98).

Deste modo, pode-se dizer, que "o Brasil e o índio são realidades apreendidas e transmitidas de modo diverso", fazem parte das fases socioculturais e temporais da colonização, bem como da tela cultural "dos sujeitos discursivos e a posição institucional donde e para que escrevem" (BARRETO, 1992, p.101).

A mesma realidade é sempre outra. Os factos, relevantes do Brasil e do índio são uma construção a partir do encontro entre os sujeitos e as coisas, uma resultante em que aquilo que se anota e transmite nasce tanto do fenomenal do Brasil e do índio, como da tela cultural, individual e social, de quem descreve, classifica e interpreta (BARRETO,1992, p.102).

Analisando por essa linha de pensamento, a descrição de um missionário estaria centrada nas problemáticas do índio, privilegiando elementos comportamentais como casamentos, crenças religiosas, educação infantil, etc., enquanto que a descrição realizada pelo colono ou funcionário do estado estaria mais focada nos aspectos materiais, dando ênfase no trabalho, tecnologia, hábitos alimentares e militares, entre outros.

Como mencionado anteriormente, cada época foi responsável por uma forma de ver e compreender o "outro", dessa forma, analisaremos um pouco mais sobre os relatos constituídos no decorrer de cada século.

As descrições feitas no início do século XVI foram responsáveis pela criação da imagem do indígena como o "bom selvagem". "O bom Selvagem é o homem, independente e sem artifícios, despido de ambições materiais, que não se preocupa em acumular riquezas ou mesmo entesourar para necessidades futuras" (CUNHA, 2011, p.280).

Varnhagen reitera essa ideia de inocência e pacificidade, afirmando: "Na hospitalidade e generosidade não havia limites, até para os mesmos inimigos, a quem, só depois de ser concedida, se tomavam as contas de se eram efetivamente ou não" (VARNHAGEN,1979, p. 44).

A Beleza física dos indígenas, o andar despido, sua longevidade, o não possuírem qualquer propriedade privada ou forma de governo, levava a crer que os nativos daquela América, aproximavam-se da perdida idade áurea da raça humana.

Pero Vaz de Caminha descreve em sua carta datada de 1500, a nudez como algo puramente inocente, afirma que "nem estimam nenhuma coisa cobrir nem mostrar suas vergonhas, e estão acerca disso em tanta inocência como estão em mostrar o rosto - inocência tal que nem quando dormem procuram maneira de cobrir suas vergonhas" (CAMINHA, 1989, p.11).

Américo Vespúcio, foi outro grande responsável pelas contribuições e descrições acerca dos nativos do novo mundo, completa o inventario básico, que será daí em diante, a base do pensamento quinhentista sobre os índios do Brasil. Seus relatos revelam um modelo acabado de todos os estereótipos literários da época, sua narrativa não foge muito às encontradas nas cartas de Colombo e Caminha "Essas pessoas andam nuas, são bonitas e têm uma cor de pele acastanhada, sendo bem construídas de corpo. Cabeças, pescoços, braços, vergonhas e pés, tanto de homens quanto de mulheres, são enfeitados com penas" (VESPÚCIO, 2003, p.41). Em suas descrições fala pela primeira vez sobre a pratica do canibalismo.

É a partir de relatos como os de Vespúcio que os pensamentos contraditórios em relação aos ameríndios evoluem e se disseminam ao longo dos séculos. Seguindo por essa mesma visão, já 
em meados do século XVI, o franciscano André Thevet, descreve em seus escritos os indígenas como canibais e cruéis (THEVET, 1978).

Já na segunda metade do século XVI, período denominado por Barreto (1992) como fase de "ocupação e fixação", o entendimento a respeito de alguns aspectos comportamentais se altera, assim que começa o processo de colonização, a nudez do índio já não aparece mais como algo ingênuo, mas sim associado a uma sensualidade ou luxuria excessiva, que os aproximaria dos animais; a falta de acumulação de bens e ambição material, ausência de domesticação de plantas e animais, ausência de propriedades privadas ou de quaisquer posses materiais passa a ser entendida como aversão ao trabalho, imprevidência e preguiça (CUNHA, 2011).

Ainda em meados do século XVI e início do XVII, surgem dois relatos de viagens com grande impacto nas cortes europeias e que logo atingiu o imaginário popular e a reflexão filosófica. Produzidos por Hans Staden e Anthony Knivet esses relatos tem como carro chefe a representação da cultura e do cotidiano dos indígenas brasileiros, sobretudo os Tupinambás e Tupiniquins, e ambos os relatos tem como centralidade as descrições e uso de imagem que relatam os rituais antropofágicos.

O relato de Hans Staden pode ser considerado um dos primeiros best-seller sobre os povos originários do Brasil no século XVI. O escritor descreve minuciosamente sua vivencia depois de mais de nove meses em que permaneceu como prisioneiro entre os Tupinambás.

A partir da leitura de sua obra publicada em 1557, posteriormente publicada em português com o nome "Duas Viagens ao Brasil", é possível ter uma ideia, dos personagens importantes do período, bem como da situação política da colônia portuguesa de sua época, tornando-se uma fonte de informações de interesse antropológico, sociológico, linguístico e cultural sobre a vida, os costumes e as crenças dos indígenas do litoral brasileiro (SCHNEIDER, 2015).

Anthony Knivet foi outro aventureiro que se tornou prisioneiro dos Tupiniquins, seu livro cuja tradução em português é "As incríveis aventuras e estranhos infortúnios de Anthony Knivet: memórias de um aventureiro inglês que em 1591 saiu de seu país com o pirata Thomas Cavadish e foi abandonado no Brasil, entre índios canibais e colonos selvagens", publicado originalmente em 1625 , conta sua saga como prisioneiro dos indígenas e dos colonos portugueses.

Os relatos de Knivet refletem uma perspectiva que foi muito usual neste período, de considerar que os colonos portugueses eram mais desumanos e mais "selvagens" do que os nativos canibais, haja vista que ele passou grande parte do tempo como escravo e prisioneiro de duas famílias portuguesas, descreve assim, toda a crueldade que sofreu nas mãos dos portugueses. Em seu relato encontra-se ainda uma minuciosa descrição do período em que passou junto aos índios Tamoios, convivência está descrita de forma muito amigável, onde é tratado como parte integrante da comunidade indígena e da qual sua presença é fundamental para tomada de decisões importantes, como por exemplo, estratégias de guerra e ataque a tribos inimigas ou mesmo aos portugueses.

Apesar de seu relato apresentar essa boa relação com os indígenas, Knivet, por sua vez não deixa escapar suas descrições daquilo que ao seu ver eram práticas brutais de canibalismo a que esses índios estavam acostumados,

Estas discussões acerca do canibalismo indígena foi ganhando adeptos e inimigos ao longo dos anos e em distintos espaços, processo este que culminou com o ensaio filosófico de Michel De Montaigne, em 1580, que, apesar de não ter conhecido o continente americano, valeu-se de relatos como o de Staden para compor sua reflexão, descrevendo algumas das mais influentes reflexões histórico-filosóficas que contrastam a vida dos índios com dilemas humanos. Como se sabe Montaigne descreveu não apenas as práticas do canibalismo, mas também fez uma importante descrição acerca dos nativos do novo mundo. Lévi-Strauss $(1991)^{1}$, considerou este

\footnotetext{
${ }^{1}$ Lévi-Strauss, Claude. História de Lince. São Paulo: Companhia das Letras, 1993 [1991].
} 
como um dos principais contributos para a reflexão, em sua época, sobre a descoberta do novo mundo.

Montaigne tem uma visão crítica acerca das questões da barbárie e selvageria. A seu ver os habitantes das novas terras são vistos como "bárbaros", pois são analisados por concepções oriundas do mundo europeu, um mundo distante tanto fisicamente como culturalmente daquele mundo novo, por não haver outra forma de se embasar e analisar o novo.

A originalidade de Montaigne está na forma como ele trabalha a questão da oposição ou dicotomia em relação ao "outro", em que os nativos não seriam apenas o "outro" do europeu. Ao contrário, enfatiza a diversidade de costumes e de experiências humanas em seus diferentes contextos, mostra as variações nos costumes e suas diferentes possibilidades de maneira que, tratando-se das culturas, "não se trata de estabelecer uma alteridade, o que seria meramente dicotômico, mas uma pluralidade de culturas". (MARCONDES, 2012, p.431).

Nos séculos XVII e XVIII ainda estava em pauta as discussões em torno do canibalismo e do índio selvagem, o processo de colonização e expansão do território brasileiro estava enraizado e criando cada dia mais forças, este processo de "desbravamento" e ocupação do território levou a um maior contato entre indígenas, missionários e colonos, contatos estes que acarretaram em sangrentos confrontos.

O processo de "entradas" sertão a dentro e o povoamento do território brasileiro no século XVII foi responsável pelo genocídio de boa parte da população indígena, os descimentos, aprisionamentos, guerras e epidemias foram os fatores determinantes neste processo.

É a partir deste momento que se intensificam as disputas entre índios, colonos e missionários. Como resultado dessas disputas foi criado em 1688 a Lei que considerava como "justa" a guerra contra os inimigos da igreja e contra índios que não reconheciam o poder da corte real (OLIVEIRA; FREIRE, 2006).

O conceito de guerra justa será implementado para justificar a captura, aprisionamento e escravização dos indígenas, obedecendo as ideologias expansionistas. Essa força de trabalho escravo proporcionou o estabelecimento dos engenhos no Nordeste e "sustentou as empresas que exploravam as drogas do sertão na Amazônia após o fim das relações de escambo das primeiras décadas do séc. XVI" (Oliveira; Freire, 2006, p.40).

Fatores econômicos e políticos da época influenciaram na criação e consolidação de uma imagem do índio bárbaro e selvagem, que se tornariam civilizados se submetidos ao trabalho e às doutrinas religiosas cristãs. Esse pensamento embasados em preceitos expansionistas, irão se constituir como elemento principal nas políticas de doutrinação indígenas pelo menos até o século XIX.

Outro grande responsável pela criação e consolidação do imaginário sobre os indígenas brasileiros foi Adolf Varnhagem, com seu livro intitulado "História Geral do Brasil". Apesar de sua obra ser criada comente em meados do século XIX, é um grande contributo para entender a visão do indígena no período colonial, pois seu trabalho tinha a pretensão de ser um olhar abrangente sobre o passado brasileiro desde 1500 , e é de certa forma uma excelente ferramenta para se analisar como perdurou no imaginário social a visão do indígena colonial até o século XIX.

\section{CONCLUSÃO}

Ao que foi exposto, já nos permite identificar representações sobre os índios no período colonial derivadas, sobretudo, de uma visão de mundo que buscava fornecer um sentido humanístico e religioso ao processo colonial. Neste cenário, surgem duas teorias sobre a humanidade dos gentios, a primeira que os considera seres humanos degradados, vivendo como bárbaros, mas que apresentavam potenciais para se tornarem cristão e a segunda teoria, na qual 
os gentios eram seres inferiores, animais incapazes de se tornarem cristãos, podendo assim ser escravizados ou mortos (OLIVEIRA; FREIRE, 2006).

É nesse contexto diacrônico que tais relatos disseminam como defende, entre outros, Marcondes, uma imagem ambígua e negativa em relação aos indígenas. Isso porque no imaginário europeu constrói-se uma "explicação sobre a natureza desses povos que é necessariamente ambivalente, e mesmo contraditória", ora valorizando sua proximidade à natureza, quase como Adâmica, ora sua selvageria e brutalidade que os aproxima dos animais. "O nobre selvagem é, ao mesmo tempo, o canibal que pratica esse horror barbaresco" (MARCONDES, 2012, p.429).

Pouco a pouco esse pensamento serve como pretexto para a "domesticação" e "humanização" do índio. A entrada sertão adentro e o desbravamento de terras habitadas por índios vira uma epopeia onde o colonizador é o instrumento principal no processo de civilização (OLIVEIRA; FREIRE, 2006, p.17).

Partindo dessas premissas civilizacional, justificou-se a conquista destes povos bárbaros pelos europeus. Seria necessário "civilizar" os "degenerados", humaniza-los, e a mudança principal estaria na alteração de seus costumes e valores, mudar seus hábitos, ensinar-lhes os valores cristãos e o meio mais eficaz seria submetendo-os ao catecismo e ao trabalho colonial.

\section{REFERÊNCIAS}

BARRETO, L. F. O Brasil e o Índio na geografia dos Descobrimentos Portugueses- século XVI. Revista da faculdade de Ciências Sociais e Humanas, 77-102. 1992.

CAMINHA, P.V. de. Carta de Pêro Vaz de Caminha ao Rei D. Manuel. Em Albuquerque, L. O reconhecimento do Brasil (1-9). Lisboa: Publicações Alfa. 1989.

CUNHA, M. C. Índios como tema do pensamento social no Brasil. Em A. Botelho, \& L. M. Schwarcz, Agenda brasileira. Temas de uma sociedade em mudança. São Paulo: Companhia das Letras. P. 278-291. 2011.

KNIVET, A. As incríveis aventuras e estranhos $s$ incríveis aventuras e estranhos infortúnios de Anthony Knivet: memórias de um aventureiro inglês que em 1591 saiu de seu país com o pirata Thomas Cavadish e foi abandonado no Brasil, entre índios canibais e colonos selvagens. Sheila Hue (org.); Vivien Lessa de Sá (trad.). Rio de Janeiro: Jorge Zahar Editor, p. 119-120. 2007.

MARCONDES, D. Montaigne, a descoberta do Novo Mundo e o ceticismo moderno. Kriterion: Revista de Filosofia, pp. 421-433. 2012, https://doi.org/10.1590/S0100-512X2012000200006.

OLIVEIRA, J. P., \& Freire, C. A. A Presença Indígena na Formação do Brasil. Brasília: Ministério da Educação, Secretaria de Educação Continuada, Alfabetização e Diversidade. 2006.

RUIVO, A. L. Corpo e Cultura: o indígena brasileiro nos relatos portugueses da segunda metade do século XVI. Lisboa: Universidade Nova de Lisboa. 2010.

SCHNEIDER, G. J. Guardiões do éden: narrativas de encontros com criaturas maravilhosas na américa portuguesa - século xvi. Juiz de Fora: Dissertação Mestrado. Universidade Federal de Juiz de Fora. 2015.

THEVET, A. As singularidades da França Antártica. São Paulo: Universidade de São Paulo. 1978. 
VARNHAGEN, F. A. de. História Geral do Brasil. Em Odália, N. Grandes Cientistas Sociais (35-117). São Paulo: Ática. 1979.

VESPÚCIO, A. Mundus Novus. As cartas que batizaram a América. São Paulo: Editora Planeta. 2003. 